\title{
Vivencias peruanas: el exilio y la Guerra Civil española
}

\author{
Olga MuÑoz CARRASCO \\ Saint Louis University (Madrid Campus) \\ omunozc1@slu.edu
}

\begin{abstract}
RESUMEN ${ }^{1}$
El exilio de escritores o intelectuales peruanos durante el siglo XX constituye un fenómeno muy destacable que nos acerca a figuras como Víctor Raúl Haya de la Torre, José Carlos Mariátegui, Magda Portal o Luis Alberto Sánchez. En este sentido, encontramos un episodio de máximo interés al acercarnos a ciertos autores que mostraron una intensa relación con la Guerra Civil española. Tal es el caso de César Moro y César Falcón, para quienes su compromiso con el bando republicano tuvo consecuencias fundamentales. Este ensayo aborda, desde un planteamiento más panorámico al comienzo, cómo la Guerra Civil española supuso un capítulo ineludible para algunos escritores peruanos.
\end{abstract}

Palabras clave: exilio, Guerra Civil española, Perú, César Falcón, César Moro.

Peruvian experiences: exile and the Spanish civil war

\begin{abstract}
The exile of Peruvians writers during the $20^{\text {th }}$ century is an outstanding phenomenon which deserves more critical attention. Intellectuals such as Víctor Raúl Haya de la Torre, José Carlos Mariátegui, Magda Portal or Luis Alberto Sánchez, just to mention a few, were compelled to live as exiles at different moments. One of the most interesting episodes in this regard arises when we approach figures such as César Falcón or César Moro, whose political engagement with the had utterly decisive consequences in their life and work. This article analyzes, beginning with a panoramic view, the intense relationship between some Peruvian writers and the Spanish Civil War.
\end{abstract}

Key words: exile, Spanish Civil War, Perú, César Falcón, César Moro.

\footnotetext{
${ }^{1}$ Este artículo se enmarca en el proyecto de investigación titulado "El impacto de la guerra civil española en la vida intelectual de Hispanoamérica" (HUM 2007-64910/FILO).
} 
La historia de las relaciones entre Perú y España encuentra un núcleo de interés fundamental en los exiliados que, durante el siglo XX, llegaron aquí en varias oleadas como consecuencia del agitadísimo panorama político en Lima. Evidentemente, salidas ya reseñables podemos hallarlas en las primeras décadas del $\mathrm{XIX}^{2}$, durante los años de la Independencia; pero el movimiento de intelectuales adquiere mayor atractivo cuando pensamos en el protagonismo de los escritores peruanos en relación con otro episodio histórico turbulento, el de la Guerra Civil española.

\section{EL EXILIO EN EL PERÚ}

Principalmente los exiliados peruanos llegan a España huyendo de la situación política en su país en dos momentos muy concretos: la toma inconstitucional del poder por parte de Augusto B. Leguía en 1919 y la permanencia en el gobierno impuesta por el general Óscar R. Benavides en 1936. Ambos periodos resultan determinantes en el compromiso por parte de algunos autores peruanos con la República española y, especialmente, con la defensa de esta postura durante la guerra.

Entre los años 1919 y 1930 Leguía, al frente del gobierno, dio a las relaciones oficiales entre Perú y España, no demasiado intensas hasta entonces, "un fuerte impulso que sería correspondido por la Dictadura de Primo de Rivera (1923-1930)" (Martínez Riaza 2004: 31) ${ }^{3}$. Varios personajes notables salen del país en esa época: José de la Riva-Agüero, aristócrata y tradicionalista encarcelado durante unas horas precisamente por Leguía, encontrará en España y en Italia su destino durante años -aunque, por posición ideológica, no será el suyo un caso representativo de participación peruana en los acontecimientos españoles de los años 30.

Víctor Raúl Haya de la Torre y José Carlos Mariátegui también hubieron de afincarse y desplegar su valiosa actividad intelectual fuera del Perú, viviendo a menudo desplazamientos como consecuencia de la repercusión continental de sus ideas. Haya de la Torre, fundador del APRA ${ }^{4}$ en México en 1924, había sido deportado por Leguía en 1923 a Panamá, mientras que Mariátegui fue forzado a elegir entre el exilio o la prisión. Finalmente salió del Perú con una "beca" del gobierno para estudiar en Italia, con la posibilidad de realizar numerosos viajes a otros países europeos, entre ellos a España.

Un caso similar, al menos durante esta época, encontramos en la escritora peruana Magda Portal, desterrada del país por su combativa oposición a Leguía. Cabe recordar su rechazo del Premio de los Juegos Florales de la Universidad de San Marcos en 1923 para no verse obligada a dirigirse al presidente, presente en el acto de entrega. Magda Portal se exilia en 1925 y se instala en Bolivia, de donde será expul-

\footnotetext{
2 Para una revisión cronológica del fenómeno del exilio peruano en tierras españolas, véase Holguín Callo (2008).

3 Completa Martínez Riaza: "El directorio de Primo de Rivera coincide con la etapa más autoritaria de Leguía, tras la reelección de 1924. Desde los círculos oficiales y a través de sectores de la elite cultural se potenciaron los vínculos institucionales y las manifestaciones simbólicas de hispanismo" (2004: 31).

4 Alianza Popular Revolucionaria Americana.
} 
sada a su vez debido a su actividad política. De vuelta al Perú se verá de nuevo exiliada en 1927, primero a Cuba y luego a México. Como denuncia Cecilia Bustamante, terminó su vida fuera del Perú en una situación económica penosa y sin el recuerdo de sus compatriotas (Bustamante 2004).

Pero si atendemos a la implicación en el devenir de la política española de la década de los treinta, sin duda la figura de César Falcón se alza sobre todas las demás. Amigo de Mariátegui desde su época de juventud en Lima, ambos colaboraron en periódicos como La Nación o El Tiempo. Fundaron juntos La Razón en 1919, publicación que fue cerrada ante la inminente salida de un artículo de Falcón contrario a Leguía. Con Mariátegui se exilió a Europa, aceptando igualmente la oferta por parte del gobierno de una subvención para venir, en su caso a España, a propagar una imagen positiva del Perú en el extranjero -función que, por cierto, nunca desempeñó. Permaneció aquí durante casi veinte años (a excepción de algunos viajes esporádicos) y salió exiliado, como tantos españoles, a Francia en $1938^{5}$; como muchos de ellos también, mostró un compromiso inalterable con la República, con la que se identificó y por la cual siguió luchando durante su destierro, ya doble: como exiliado peruano en España y como exiliado español en París.

Pero antes de abordar cómo y con qué matices algunos de estos autores tomaron partido durante la Guerra Civil española, saltemos hacia ese segundo momento del exilio peruano en España que se produce bien entrados los años treinta. Más en concreto, el 11 de octubre de 1936 tuvieron lugar unas elecciones en el Perú que fueron anuladas en los días siguientes por Benavides, en el poder desde 1933, debido a la clara victoria de Luis Antonio Eguiguren, candidato apoyado clandestinamente por el APRA. El general Benavides quedó pues al frente del gobierno nuevamente, gracias a una suerte de prórroga que se extendió hasta 1939.

El historiador y líder aprista Luis Alberto Sánchez representa con su salida del país al grupo de intelectuales que, instalados en Chile, desarrollaron una memorable labor intelectual desde la plataforma de la editorial Ercilla, revista en la que también colaboraron Ciro Alegría, Manuel Seoane o Alberto Hidalgo, entre otros muchos peruanos. Lo cierto es que Sánchez fue deportado del Perú antes del 36, durante el primer mandato de Benavides, y cuenta él mismo en qué términos se configuraba el exilio por entonces:

Estaba yo incomunicado en el nauseabundo calabozo 4 de la antigua Intendencia de Lima, en la calle Pescadería, cuando una noche, se presentó en mi yasija [sic], un pariente del dictador general Benavides, presidente de turno. Me informó que éste había decidido deportarme y que, por especial deferencia, yo podría escoger a donde [sic] quería que me fletasen (expresión más exacta que "deportasen") y como ya tenía asegurado el trabajo con [Laureano] Rodrigo en la editorial Ercilla, respondí: "Preferiría que me mandaran al Norte". Según estaba previsto me dispararon al Sur; laudable contradicción. (Sánchez 1975: 33-34)

\footnotetext{
5 Para una biografía más detallada y completa de César Falcón, consúltese la introducción del estudio de Martínez Riaza (2004).
} 
Otro de los intelectuales afectado por el ambiente represivo de Benavides fue José María Arguedas: “Estuve en 'El Sexto' ocho meses, dos en la Intendencia y un mes y medio en el Hospital" (Merino de Zela s/f: 9). Efectivamente, estuvo preso entre 1937 y 1938 tras la visita de un enviado de Mussolini a la Universidad de San Marcos, a quien los estudiantes primero abuchearon por los bombardeos de la aviación italiana sobre España y después arrojaron a la pileta del patio central (Merino de Zela s/f: 9).

Emilio Adolfo Westphalen sufrió también una temporada de prisión a consecuencia de su labor opositora al gobierno y César Moro tuvo que salir como exiliado político hacia México tras la confiscación por parte de la policía de todos los ejemplares de CADRE que guardaba en su domicilio. Esta revista, CADRE (Comité de Amigos de los Defensores de la República Española), supuso en el Perú uno de los escasísimos llamamientos claros a favor de la República española. Su publicación y difusión se produjo de manera clandestina y, aún así, sus impulsores padecieron represalias.

\section{LA GUERRA CIVIL ESPAÑOLA O CÓMO PERTENECER A UNA PATRIA EN LUCHA}

Como puede apreciarse a primera vista, los años de gobierno militar de Benavides en el Perú coinciden plenamente con los de la guerra en España y, como cabía esperar, esta situación determinó la posición del Perú ante el conflicto español. Con un discurso anclado en la patria, Cristo y la tradición, la postura oficial del gobierno peruano fue desde un primer momento de apoyo a los rebeldes. ¿Quién, además, podía asegurar que no sucedería algo similar en el Perú, dada la actividad del comunismo en el país por parte de los apristas? A este planteamiento maniqueo responde también la izquierda peruana. Luis Alberto Sánchez llegó a escribir mucho tiempo después sobre cómo el propio Haya de la Torre "no se mostraba muy resuelto a tomar partido en aquella contienda; [...] argumentaba siempre sobre la diferencia esencial entre los intereses europeos y los americanos" (Sánchez 1987: 160). El número 3 de CADRE se hace eco de esta peculiar situación y denuncia la actitud insolidaria de ciertos intelectuales peruanos con España:

Ciro Alegría, Manuel Seoane, y L. A. Sánchez, conocidos intelectuales y líderes del aprismo deberían asistir a este Congreso [Internacional de Escritores para la Defensa de la Cultura] al cual se les había invitado especialmente. Pero se han negado a ello argumentando que sus deberes en Indo américa [sic] no les permite [sic] su concurrencia. Es de lamentar que el Partido mayoritario del Perú no se haga presente en este Congreso; ello le hubiera permitido exponer ante todo el mundo los puntos anti-fascista [sic] de su ideario; hacer conocer la situación del Perú y tomar una posición definitiva por España Repúblicana [sic], con indudables proyecciones para el movimiento democrático del Perú tan ligado a la causa que defiende el pueblo español. Hubiera hecho mucho más por la causa de Indoamérica y del Perú la concurrencia de los líderes apristas en Valencia que su permanencia en Chile o Argentina. Y así como nosotros piensa la mayoría del pueblo peruano. (CADRE 1937) 
Además, el hecho de respaldar a los republicanos vendría a confirmar las insinuaciones vertidas por casi todos los periódicos del momento con respecto a la relación del APRA con el comunismo internacional. Casi sin excepción, la prensa se hizo eco de los asesinatos y persecuciones de religiosos en España, de forma que se logró una identificación del Perú con su componente hispánico más tradicional.

Sin embargo, justamente varios de los escritores exiliados entonces se sienten llamados por la guerra española y, gracias a ella, reconsideran su conflictiva relación con la lejana madre patria. Un ejemplo bien explícito de esta actitud la muestra Magda Portal, quien en un largo poema publicado en Costa Rica plantea la evolución de su sentir con respecto a España. He aquí unos versos ilustrativos:

te odiaba por la herencia de tu sangre azul -sangre decrépita- que llevamos los americanos como una maldición y contra la que insurgimos negándola, para sentirnos dignos de nuestro destino; [...].

[ahora te amo] por tus milicianos, que marchan a la muerte y a la victoria -alegres- como a su primera fiesta; por tus poetas mártires y por tus artistas proletarios. (Portal 1938: 253)

El caso de César Moro se acerca más a la figura del intelectual coherentemente comprometido con la causa de la República. Hay que recordar que Moro percibió su existencia como un exilio integral: era en cierto sentido un exiliado social por homosexual e incluso un exiliado de su propia lengua ya que, a excepción de La tortuga ecuestre, toda su obra fue escrita y publicada en francés ${ }^{6}$. Partiendo de este completo desarraigo, podemos detectar en su adhesión al bando republicano un sentido de pertenencia en cierta manera insólito. Moro se siente íntimamente apelado por la lucha de España, y su respuesta implica una defensa enarbolada desde lo personal y lo político, así como desde su condición de peruano e hispanoamericano.

La trayectoria del Boletín de CADRE es breve pero crucial, tanto por lo que significa en la cerrada atmósfera política peruana como por la relevancia de sus promotores: Westphalen, Moro y Manuel Moreno Jimeno. CADRE vio la luz presumiblemente en cuatro ocasiones -hay cierta discrepancia en el número exacto-, siempre con casi todos sus artículos sin firmar. Ni siquiera aparece el nombre de los fundadores de la publicación, lo que impide asignar los trabajos con seguridad. En todo caso, no es arriesgado pensar que Moro, Westphalen y Moreno Jimeno suscribían todas las opiniones recogidas en la revista. Gracias a ellas podemos comprobar el grado de implicación de Moro en el conflicto bélico:

A raíz de la insurrección de las derechas de España, acaudilladas por el fascismo y por los generales, contra el gobierno constitucional, y previendo perfectamente,

\footnotetext{
6 "Se puede conjeturar que el poeta adoptó la otra lengua precisamente por extranjera y por extraña y porque él era un poeta extrañado y en cierto modo extranjero de nacimiento, si se puede decir: y yo he dicho en un breve ensayo que Moro hallaba su patria en sus amigos -igual Lima, París o México-, tierra móvil y sin fronteras que él llevaba en el alma como otros llevan en una bolsita un puñado de tierra del país natal". (Ferrari 2003)
} 
dado el carácter social de la lucha que el pueblo español y sus legítimos gobernantes, en su defensa de la república democrática, se verían acosados por la coalición internacional de todas las fuerzas fascistas, un grupo de ciudadanos que en el Perú bregamos por la misma causa, nos sentimos imperiosa y urgentemente llamados a acudir en auxilio material y moral de nuestros compañeros y hermanos de la Península. Y entusiastamente nos constituimos en "Comité de Amigos de los Defensores de la República Española" (CADRE) encarando inmediatamente la necesidad de apoyar por todos los medios a nuestro alcance, al gobierno y al pueblo españoles en su heroica contienda contra el bandidaje y la barbarie del fascismo internacional. (CADRE 1936b: 1)

Moro arenga desde CADRE, organiza colectas de dinero para los republicanos y exhibe una militancia que pretende extender al pueblo peruano. Nada antes había propiciado una entrega así a lo colectivo ni una identificación similar con una causa

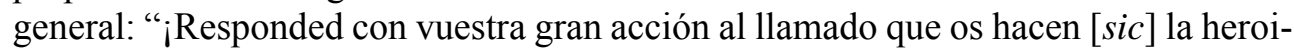
ca juventud de España! ¡Alistaos en el gran ejército de la paz y del anti-fascismo del mundo entero!" (CADRE 1936c).

Las consecuencias de esta defensa explícita y clandestina de la República española fueron, como ya comenté, la cárcel para Westphalen y la salida del Perú para Moro, quien añade el exilio territorial a sus desarraigos anteriores. Ambos poetas, desde circunstancias personales muy diferentes, ejemplifican la independencia artística y la beligerancia revolucionaria que, en 1938, defendieran André Breton, León Trotsky y Diego Rivera en su manifiesto "Por un arte revolucionario independiente", aparecido en México -donde, por cierto, se encontraba residiendo ya César Moro-.

La vivencia del exilio y de la guerra civil española de César Falcón ofrece pocos puntos en común con la ya expuesta de Moro. Falcón tuvo una inmersión absoluta en la España que lo recibió en 1919. Mientras que Moro alude a las terribles condiciones políticas del Perú al hilo de su reflexión sobre España o Europa, Falcón va a desentenderse completamente de la situación peruana una vez establecido aquí. Tal vez por eso haya sido tan poco editado en su país de origen. En España, por otra parte, nunca dejó de ser considerado un escritor hispanoamericano, de manera que tampoco existen demasiadas referencias a su labor, o al menos no en la proporción en que cabría esperar por su actividad política, editorial y literaria. En todo caso, su presencia en el ambiente cultural español puede constatarse mucho antes de la guerra. Ya en 1921 publicaba en El Liberal de Madrid la siguiente reflexión, justificación quizá de la condición de español que asumió desde muy pronto:

Yo no he creído nunca en la historia hispanoamericana. O mejor dicho, no he creído, ni creo, que la América española tenga historia. Que la tenga en el sentido en que la estudian, comentan y debaten los indigestos historiadores sudamericanos. Y mucho menos he creído, desde luego, que la obra de éstos tenga alguna importancia. La tal Historia de América, según mi humilde concepto, no es sino un episodio de la Historia de España. Y no por cierto el episodio más importante. (Martínez Riaza 2004: 135) 
Como cualquier español involucrado intensamente en política, publicó y argumentó en respuesta a los acontecimientos del país. Escribió contra la dictadura de Primo de Rivera y pronto defendió una postura republicana, como comprobamos en este artículo de 1926 en Amauta:

La monarquía $[\ldots]$ desprecia y ha despreciado siempre a los pueblos hispanoamericanos. Porque la monarquía no puede sentir, ni ha sentido nunca, la emoción de nuestra raza. La monarquía es extranjera. Francesa o austriaca. [...] Por todo esto, la lucha contra la monarquía española es un deber común a todos los pueblos hispánicos. España es la esencia de nuestra nacionalidad, su motor y su núcleo. Gran parte de la decadencia de los pueblos hispanoamericanos se debe a la decadencia de España. (Martínez Riaza 2004: 144)

Falcón, además, recoge el agitado acontecer de la política española entre 1933 y 1934 en Por la ruta sin horizonte (México, 1961). Esta novela pretendía formar parte de una serie titulada En la Perspectiva de España de la que, finalmente, sólo escribió el primer eslabón ${ }^{7}$. Junto con ella, encontramos su visión del panorama político y social de la República en El mundo que agoniza (México, 1945), Madrid (obra coral publicada en España en 1938) y Crítica a la Revolución Española (Madrid, 1931).

Afiliado al Partido Comunista en 1933, participó como periodista en Mundo Obrero - del que fue editor y director- y Frente Rojo. Promovió igualmente empresas culturales como Teatro Proletario y Altavoz del Frente, conjunto de actividades culturales que acercaban libros y espectáculos a los soldados en el frente y que, además, incluía la publicación de un semanario del mismo título. El compromiso político mantenido por Falcón durante toda su vida se muestra pues en toda su plenitud con el estallido de la Guerra Civil española, cuyos trazos dibuja expresivamente en sus publicaciones de entonces:

A pesar de los buenos deseos del Gobierno, de su tolerante pacifismo, se derramará sangre en España. Las tierras ásperas de Castilla volverán a beber la savia caliente de los hombres; se empaparán de nuevo las calles, los campos y los montes. ¿Qué han hecho desde hace tres siglos las arterias del pueblo español, sino verterse copiosamente en la tierra? [...] Morirán miles de hombres, decenas de miles quedarán mutilados; caerán mujeres y niños; campos y ciudades, fábricas, aldeas, España íntegra quedará destrozada, en escombros. Nada alumbra en la naturaleza sin dolor ni desgarro. En España alborea una vida nueva, gloriosa y feliz. Surge de sus entrañas con la vasta y sangrienta esplendidez de una aurora. (Martínez Riaza 2004: 174)

César Falcón salió de España forzado por los acontecimientos en 1938. Pero su compleja identidad nacional sufrió todavía otros avatares, ya que con el final de la

${ }^{7}$ Esta primera novela abarca desde la elecciones de 1933 hasta la llegada de la derecha al gobierno en 1934. Los títulos de las siguientes estaban ya decididos: Entre la noche y el fuego, Noviembre iluminado, Camino hacia el fin y Camino hacia el futuro (Martínez Riaza 2004: 84). 
guerra quedó invalidada la ciudadanía española que la República le había reconocido. Desgraciadamente, esta anulación no le sirvió para lograr el regreso al Perú desde su exilio en Francia, ya que allá lo consideraban español. Falcón continuó desde París su labor en contra del fascismo y en recuerdo de los vencidos, aunque obtuvo poco éxito en sus gestiones para facilitar la llegada de exiliados españoles al Perú $^{8}$ (Martínez Riaza 2004: 20). Colaboró también con La Voz de Madrid, periódico en español fundado en París en 1938. En 1940 sale hacia Estados Unidos con la intención de gestionar desde allí la vuelta al Perú. Con la llegada al poder de Manuel Prado en 1939 se le permitió entrar de nuevo en su país de origen y, poco después, se le concedió la nacionalidad peruana. Tras ciertos enfrentamientos con Manuel A. Odría, salió nuevamente del Perú para acabar residiendo en México donde, tras muchas dificultades, obtuvo la naturalización mexicana. Tampoco allá se desvinculó de España: sobre ella siguió escribiendo en las dos revistas que editó, Rangos e Historia Nueva.

\section{LA ESPAÑA SOÑADA COMO RAÍZ}

Con el estudio del exilio en ciertos escritores peruanos del siglo XX, constatamos cómo, desde trayectorias muy distintas, se siente la necesidad común de dar respuesta al acontecimiento ineludible de la Guerra Civil española. Y en esta respuesta hallamos tantas posiciones como autores, aunque hay que resaltar la de aquellos para quienes el conflicto bélico supuso un elemento crucial en la configuración de su propia identidad. Mientras que Magda Portal o Luis Alberto Sánchez, fuera del Perú y con mayor o menor pasión, defienden con su palabra la causa republicana, César Falcón y César Moro hallan en la lucha contra los alzados en España un modo de pertenencia e integración poco habituales en sus textos hasta entonces. Falcón encuentra en la situación española el fértil abono que hará crecer unas inquietudes sociales y políticas traídas desde muy joven. César Moro, por su parte, exiliado de tantos espacios reales o metafóricos, arraigará en los ideales de una España lejana y lanzará desde $C A D R E$ un grito colectivo extraño a su solitaria condición de desterrado. Durante un breve tiempo, desde una convicción inalterable, Moro y Falcón borran su exilio y echan raíces para ofrecer con fuerza, como leemos en CADRE, “i[n]uestra voz, nuestros brazos trépidos e inquebrantables a la acción!” (CADRE 1937).

\section{BIBLIOGRAFÍA}

BUSTAMANTE, Cecilia (2004): "Magda Portal y sus poderes. La mujer peruana y su relación con las ideologías y el poder”. El Peruano, 26 de enero de 2004.

\footnotetext{
8 "En la estancia e el Perú, entre 1940 y 1942, fue uno de los impulsores de Garcilaso, órgano de la Asociación Nacional de Escritores, Artistas e Intelectuales del Perú que se editó en Lima entre 1940 y 1942 para luchar contra el fascismo y apoyar a los vencidos en la Guerra Civil española". (Martínez Riaza 2004: 21)
} 
CADRE (1936a): Boletín del Comité Amigo de los Defensores de la República Española. Sin numeración, sin fecha, sin ciudad de publicación.

- (1936b): CADRE, núm. 1, octubre. Sin ciudad de publicación.

- (1936c): Boletín de los Amigos de los Defensores de la República Española, núm. 2, diciembre. Sin ciudad de publicación.

- (1937): Boletín de la 'CADRE' (Comité de Amigos de los Defensores de la República Española), núm. 3, julio. Lima.

FALCÓN, César (1961): "Por la ruta sin horizonte", en En la perspectiva de España (I). México: Historia Nueva.

FERRARI, Américo (2003): “César Moro y su obra poética” [en línea]. Jornal de poesia: Banda hispânica. En: http://www.revista.agulha.nom.br/bh22moro2.htm [Consulta: febrero de 2011].

HOLGUÍN CALLO, Oswaldo (2008): "Los peruanos y el exilio español en los siglos XIX y XX: Apuntes”. Revista de estudios colombinos, núm. 4, pp. 75-90.

MARTÍNEZ RIAZA, Ascensión (2004): ¡Por la república! La apuesta política y cultural del peruano César Falcón en España, 1919-1939. Lima: Instituto de Estudios Peruanos.

MERINO DE ZELA, Mildred E. (s/f): José María Arguedas. Vida y obra. Sin ciudad de publicación: sin editorial.

PORTAL, Magda (1938): "España nuestra". Repertorio Americano. Seminario de Cultura Hispánica, XXXV, abril, p. 16.

SÁNCHEZ, Luis Alberto (1975): Visto y vivido en Chile. Bitácora chilena: 1930-1970. Lima: Editoriales Chilenas Unidas.

- (1987): Testimonio personal, 2. El purgatorio 1931-1945. Lima: Mosca Azul Editores. 